\title{
Unequal Conditions of Care and the Implications for Social Policies on Young Carers
}

\author{
Chloe Alexander ${ }^{1}$ (D) \\ Accepted: 18 July 2021 / Published online: 17 August 2021 \\ (c) The Author(s) 2021
}

\begin{abstract}
Young carers are the subject of public policies in the UK, which aim to address their needs as a group experiencing disadvantage relating to their caring role. These policies are implemented in a way that aims to improve their health and their educational and social opportunities, but left unaddressed is a wider context of inequalities. Nevertheless, inequalities are a feature of the terrain upon which social policies for young carers are developed and implemented. Evaluation of the ways that young carers and their families are impacted by public policies demands an understanding of those inequalities. Academic knowledge of how experiences diverge as a result of multiple intersecting inequalities is so far limited. This paper reports from a study that aimed to contribute greater understanding of the interaction between inequalities, young carers, family life and social policies in England. Ethnographic research methods created a record of care, family life and the impact of social policies. Unequal conditions of care are an important feature of the lives of young people and their families with on-going caring responsibilities. Young carers and their families positioned at the intersection of inequalities of 'race'/ethnicity, class and disability had different and unequal experiences of support. The paper discusses these findings and explores the implications for social policies and social work practice.
\end{abstract}

Keywords Young carers $\cdot$ Inequality $\cdot$ Intersectionality $\cdot$ Ethnicity $\cdot$ Class $\cdot$ Disability

English governments have recognised children's involvement in care work, with policies at a local and national level. Children are defined as young carers for the purposes of key legislation when they provide care unpaid and are under the age of 18. During the last 25 years, these policies have sought to support those children and to limit the ways that care work impacts negatively on their lives (Aldridge, 2018). A growing field of research on children carrying out unpaid care work for parents, siblings and other relatives has presented the shared experiences of children as 'young carers' and engaged in dialogue with policy-makers on the ways that young carers are disadvantaged (Leu \& Becker, 2017). This paper seeks to extend our understanding of young carers and inequality by introducing the concept of unequal conditions of care. I propose this framework for considering multiple intersecting inequalities alongside the consideration of children's differing relationship to care work. By discussing

Chloe Alexander

c.j.1.alexander.1@bham.ac.uk

1 University of Birmingham, Birmingham, UK findings from an ethnography of young carers' family life, I explore children's and families' experiences as embedded in differing conditions of care. I consider how policies are formulated and operating in response to an understanding of young carers and their families without significant consideration of wider inequalities. This leaves a problem of reproducing inequalities by ignoring different conditions of care amongst young carers. I discuss findings on 'race'/ ethnicity and class and consider the ways that policies in England interact with inequalities to the detriment of young carers' experience of support.

\section{Young Carers in England}

In England, many children are involved in care work as part of family life (ONS, 2013), in common with children around the world (Camiletti et al., 2018). Research on young carers has strengthened understanding of the number of children that are involved in unpaid care work and the nature of their experiences as care providers. It is a perspective that has been developed particularly in the UK and applied to other 
contexts (Leu \& Becker, 2017). The young carer concept, based on research pursued in Minority World countries dominates the ways we think about and measure the phenomenon of children's care work (Evans \& Becker, 2019). It remains challenging and, to a degree, contested, to estimate the number of young carers (Kelly et al., 2017). This has become increasingly important as policy makers have been called on to respond to this group's needs for support and to then evaluate the reach, impact and comprehensiveness of services for young carers in England. We can be informed by measure such as the 2011 Census in the UK. The census counted 149,929 children as young carers in England and Wales, equating to $2.1 \%$ of young people aged five to 17 years old as young carers (ONS, 2013). Other studies, including those that ask children to report on their involvement in unpaid care, rather than relying an adult in the family to respond on their behalf, find higher prevalence, for example $4.5 \%$ of children (Vizard et al., 2019). The research indicates that young carers are there in significant numbers and that there is a strong case for providing them with support services.

Two pieces of legislation, the Care Act 2014 and the Children and Families Act 2014, set a policy framework for supporting young carers in England. These are seen as leading global policy responses to the concerns about children as young carers (Carers Trust \& University of Sussex, 2021). Children that provide unpaid care are expected to be identified by the local authority, have their needs assessed and could then be offered services. Social care services for adults and children are expected to meet the care needs of the whole family so that the degree of care provided by children in the family could be reduced and any negative impacts alleviated or prevented. However, in contrast with the stated aim, services for young carers are known to be reaching only a fraction of the intended population (Children's Commissioner, 2016). For those young carers that are receiving support, this exacerbates and entrenches existing inequalities (Alexander, 2021). Services that might be expected to support an adult that they care for, for example, a parent, are greatly restricted (Brimblecombe et al., 2020). The specialist services for young carers are reported to be highly valued (Cheesbrough et al., 2017; Sempik \& Becker, 2013) but are unlikely to be widely available.

For the families that are in contact with services, whether as a young carer or, for other family members, as people with assessed care needs, there is a lack of research that explores the ways that young carers' experienced are embedded family relationships. Only a few studies evaluate services and provision for young carers (Butler \& Astbury, 2006; Cheesbrough et al., 2017; Thomas et al., 2003). As we understand more about the lives of young carers from a growing body of research, it is clear that there is a lack of research on the delivery of services to the families of young carers. My research delves into the ways that the relationships and the multiple perspectives held within families can shed light on the delivery of services to young carers.

Another gap in the research is on young carers and their families in the context of inequalities. There is a lack of studies that examine the experience of young carers in relation to class and 'race' (Aldridge, 2018; Jones et al., 2002). Some recent studies have explored the subject of young carers and poverty (Vizard et al., 2019) or as LGBTQ + young adults (Traynor, 2016). Research into what categories of social difference, such as age and disability, mean for young carers has been added to the debate about how to understand children's relationships to care. Amongst the most recent studies of young carers, some have introduced intersectionality theory as a reference point (Akkan, 2020; Alexander, 2021; Hamilton \& Cass, 2017; Kelly et al., 2017).

A concern about inequality has driven much research on young carers, however, this has been orientated towards an inequality between children that are young carers and children that are not. To a lesser extent there is also a body of research that explores that differences between children who provide different types of care or whose care is focussed on particular family members (Santini et al., 2020; Aldridge \& Becker, 2003). Young carers were found to carry out substantially more unpaid work at home compared to children that were not young carers and are concerned about their future opportunities (Warren, 2007). Children and young people with caring responsibilities are found to face additional barriers in terms of employment and education, and experience worse health, with additional complexities in the phase of young adulthood (Alexander, 2015; Brimblecombe et al., 2020).

\section{Unequal Conditions of Care}

The concept of unequal conditions of care is introduced here. It seeks to complement the understanding of children's experience of care and knowledge of the ways that care impacts on their lives. It does this by framing an analysis of the inequalities that affect care needs, care practices, care resources and care relationships. I work with the 'unequal conditions of care' concept by analysing the interaction between care practices and the multiple inequalities in a particular historical context, acknowledging that both care and inequalities are changing and dynamic.

It is a framework for questioning and exploring the conditions under which people establish care practices. Care is understood as the historically-specific practices of replenishing people's capacity to live, shaped by social relations. Inequalities are understood as intersecting structures of power relations, drawing on scholarship on intersecting inequalities of 'race'/ethnicity, gender, class, disability, age and sexuality (Crenshaw, 1989; Hancock, 
2016; Hill Collins \& Bilge, 2016) that shape care (Shelton \& John, 1996) and global care chains (Ehrenreich \& Hochschild, 2003). It also resonates with an ecological perspective (Bronfenbrenner, 1979) prompting us to look at the wider environment in which care is established and within which it may change. We can avoid the conflation of social inequalities with the differences in care practices. If we ignore the unequal conditions of care there is a risk that we miss those factors in our analysis.

The unequal conditions of care framework is used to report and discuss finding from my ethnographic study of young carers and their families in the West Midlands. The experience of care for young carers participating in the study was shaped by a range of conditions. Young carers, their siblings and parents spoke about the impact of inequalities on their needs, the resources they could draw on, resources that were unavailable or came with strings attached. Reporting on the analysis of ethnographic data, I focus here on class, 'race'/ethnicity and citizenship-status as intersecting inequalities that had an impact on the conditions of care for young carers and their families. However, it is important to note that there were also other areas of intersecting inequalities that are not reported here, for example, those relating to sexuality, disability and gender. Heeding the political legacy of intersectionality theory (Tomlinson, 2018), which is discussed further below, this paper focusses the discussion on 'race'/ethnicity and class, without space to also present findings on the complex breadth of categories of social difference.

An analysis of the unequal conditions of care can also be used as the basis for discussing ways of improving young carers' circumstances. Policy discussions about young carers frequently attend to the ways that children are under pressure to become involved in care work because of poorly designed or inadequate services. They are concerns about their lack of access to crucial resources, deprivation and isolation. Analysing young carers and the unequal conditions of care that surround them can provide new perspectives. We can ask, what wider conditions of care could be changed that would improve young carers' circumstances? How do young carers use their social location, for example, drawing on positions of privilege as a resource for their caring role? What does a context of inequality mean for the continued stigmatisation of unpaid care work? While comparative studies of young carers have made the case for recognising children's rights to be involved in family care (Carers Trust \& University of Sussex, 2021), we can use the unequal conditions of care framework to be critical of the inequalities that undermine, penalise and impoverish children's involvement in care. There is the potential for more nuanced perspectives on children's relationship to the young carer role in the context of inequalities that are being contested, moderated or intensified by changes in policies.
Intersecting Inequalities and Young Carers

The research presented here explored inequalities informed by intersectionality theory (Crenshaw, 1989) and through the design, the fieldwork and analysis I considered a wide range of categories of social difference. Examples of categories of social difference are class, ethnicity, 'race' and class. These were understood as social structures that conceptually arrange people in hierarchical ways (Hancock, 2016; Hill Collins \& Bilge, 2016; Mirza, 2015). Categories are explicitly or implicitly referenced in social interactions that create knowledge of an individual's relationship to society (Hill Collins \& Bilge, 2016). An overarching term, social location, describes the collective effect of these structures on individuals or groups. Categories of social difference are used and understood in varied ways within epistemological and theoretical traditions but in the young carer literature they are often seen as determining people's lives by reducing people to positions of low status or at other times drawing people together around particular forms of a social category as the basis for collective action and celebration. However, there has been little research that explores the operation of multiple categories of social difference in the lives of young carers and their families, with the notable exception of Jones et al. (2002), or that delves deeper into the theorisation of difference and inequality amongst young carers.

The development of intersectional approaches has been led by Black feminist theorists who have called for a reframing of theory and empirical research to strengthen the engagement with the social experience of categories such as gender, 'race', class and sexuality (Cohambee River Collective, 1983; Crenshaw, 1989; Hill Collins \& Bilge, 2016; Mirza, 2015). This literature critiques the limitations of existing scholarship that excludes and undermine knowledge of Black women and their experiences as women, as working class, as queer and their relationship to other categories of social difference (Crenshaw, 1989; Hill Collins \& Bilge, 2016; Lorde, 1984). This diminishes understanding of gender relations, racism, class structures, sexuality and other forms of inequality (Spelman, 1988). Tomlinson describes intersectionality as a mid-level theory, which adds nuance to understandings of a global "theory for antisubordination and social change", (Tomlinson, 2018, p. 2). Whilst intersectionality powerfully supports analytical engagement with categories of social difference, it is connected to a political and theoretical project of debating and securing social justice.

The existing literature on young carers seeks to connect data to an analysis of categories of social difference through a range of research questions and methods. This can be strengthened by engaging with intersectionality 
theory because it supports a fuller understanding of the ways that an individual's relationship to multiple categories is experienced, rather than seeking to artificially distinguish them. It provides a more robust account of the collective experience of inequality. It also challenges us to represent people in subordinated positions and to articulate the operation of privilege in people's lives, rather than allowing it to remain obscure.

\section{Methodology}

The subject matter of this study is complex, with interwoven factors because it sets out to explore multiple intersecting inequalities and to understand the relationships and practices of family life for the duration of a series of months. The choice of an ethnographic methodology supported the investigation of the nuances of this subject matter, especially in the absence of previous studies that address this area. It appears that this methodology has not featured in the young carers literature, however, it has been used to study children's experience of care work and family life more broadly (Brannen et al., 2000; Gabb, 2008).

Ethnography is a qualitative research method, centred on the practices of observation and participation, which aims to immerse the researcher within a community to explain the perspectives of insiders, whilst using their outsider perspective and research skills to create new knowledge (Geertz, 1973). The constructivist paradigm of ethnography is the starting point for this project. My approach makes use of the flexibility in this method and the potential for developing ethical, knowledge-rich relationships through which theoretical questions can be explored. Central to the idea of ethnography is the researcher's journey to join a group and understand it, after which the researcher will often step away in order to reflect and write about the subject of study (Hammersley \& Atkinson, 2007). This process is recorded, largely through fieldnotes and written reflections, to capture different moments through the process (Lareau, 2011; Spradley, 1980), including the development of new understandings and the creation of relationships that enable it to proceed. The researcher is unavoidably a prominent participant in the research landscape, calling for reflexivity as a crucial element in fieldwork and analysis (Aull Davies, 1999; Hammersley \& Atkinson, 2007).

The ethnographic methodology has the benefit of allowing the study to work with participants over time to develop richer data and allow for families to refine the methods alongside the researcher. It supported the engagement of young carers alongside their families in order to give a fuller picture of care within relationships. It also provides data from observations, complementing care talk with care observations, as recorded in fieldnotes. At the same time it is shaped by the positionality of the researcher, as will be discussed further, and its depth means that it was focussed on a small number of participants.

The study was carried out 2017-19 and had five phases, through which the research question evolved in tandem with the development and applications of methods. Firstly, there was a planning phase in which ethnography was selected after consideration of a range of qualitative methods. This phase also included gaining approval for fieldwork to proceed from the university Ethical Review Committee. The second phase continued alongside the planning phase, during which I volunteered with three young carers projects in the West Midlands region of England. The third phase was recruitment of participants, followed by a fourth phase of fieldwork. The final phase was the end of fieldwork, analysis and writing of the ethnography.

I set out to study action in people's homes, considered to be private spaces, where people are deciding on what work should be done and who does it. Policies assert that this and other behaviour in private homes matters to people outside those demarked spaces (Crossley, 2016; James \& James, 2001; Parr, 2017). The collective effects of family life are to create patterns such as gender and class inequalities, as well as being subject to and absorbing those inequalities (Marx Ferree, 1990; Shelton \& John, 1996). Private spaces are important for understanding the process by which inequalities of gender, 'race', class, disability etc. are manifested (Oakley, 1974; Yeandle et al., 2017). The back and forth of ideas about who should do care work, which turn into the inequalities of care work, calls for us to establish that there is a complex relationship between the distribution of care work, inequalities and services that interact with families.

Family life, through the eyes and ears of the researcher, provides data for policy analysis. In this case, the data comes from the family life of five young carers: Aidan, Alia, Rosie, Sapphire, XD who participated in an ethnographic research project (see Table 1). ${ }^{1}$ The group of participants that chose to join the research project gave insight into a range of caring relationships, including those that in which individuals were simultaneously being classified as care provider and care recipient. Aidan was a young carer in relation to his mother who had experienced mental health problems but his younger brother and mother were classified as his carers because of his Asperger Spectrum Disorder. Alia was a sibling carer for her older sister. XD was a carer for his mother because of her experience of depression. Rosie was a sibling carer for her older sister. Sapphire was classified as a young carer because of her role supporting her father,

\footnotetext{
1 University of Birmingham Ethical Review Reference Number: ERN_17-1247.
} 
Table 1 Details of young carers and their families

\begin{tabular}{|c|c|c|c|c|c|}
\hline Young carer & Parents & Siblings & $\begin{array}{l}\text { Care relationship focussed } \\
\text { on by services }\end{array}$ & $\begin{array}{l}\text { Ethnicity (using UK Cen- } \\
\text { sus categories) }\end{array}$ & Class \\
\hline Aidan & Marie (mother) & Joey (younger brother) & $\begin{array}{l}\text { Aidan as young carer to } \\
\text { mother, Marie as parent } \\
\text { carer to Aidan, Joey as } \\
\text { young carer to Aidan }\end{array}$ & White (British) & Working class \\
\hline Alia & $\begin{array}{l}\text { Kaya (mother) } \\
\text { Ben (father) }\end{array}$ & Amber (older sister) & $\begin{array}{l}\text { Alia as young carer to } \\
\text { older sister; Kaya and } \\
\text { Ben as parent carers }\end{array}$ & Asian British (Pakistani) & Middle class \\
\hline $\mathrm{XD}$ & Tizzy (mother) & & $\begin{array}{l}\mathrm{XD} \text { as young carer to } \\
\text { mother }\end{array}$ & Black (African) & Middle class \\
\hline Rosie & Dominique (mother) & Poppy (younger sister) & $\begin{array}{l}\text { Rosie as young carer for } \\
\text { sister; Dominique as par- } \\
\text { ent carer for Poppy }\end{array}$ & $\begin{array}{l}\text { Mixed (White and } \\
\text { Asian)_-Rosie and } \\
\text { Poppy } \\
\text { White (British)_- } \\
\text { Dominique }\end{array}$ & Middle class \\
\hline Sapphire & $\begin{array}{l}\text { Becky (mother), Chris } \\
\text { (father) }\end{array}$ & $\begin{array}{l}\text { Jane (sister), Luke } \\
\text { (brother) }\end{array}$ & $\begin{array}{l}\text { Sapphire as young carer to } \\
\text { father and siblings }\end{array}$ & $\begin{array}{l}\text { White (any other white } \\
\text { background) }\end{array}$ & Working class \\
\hline
\end{tabular}

who had had a stroke, and her two siblings who had special educational needs.

The participants were recruited in March 2018, following a period in which I met children and young people who attended a local young carers group. At these groups I was in the role of a volunteer, although I was also able to discuss my research plans and discuss these with staff and the young people in attendance. This earlier volunteer phase lasted six months and it provided background information on local provision for young carers, gave opportunities to introduce the study and get feedback from children and young people on potential participation.

The recruitment process was started during a phase of volunteering. A number of young carers expressed interest in the research process and from this group I selected a sample that was diverse in terms of family care needs, demographic characteristics and being located in different areas around the West Midlands region. Their families were approached by sending information by post explaining the aims of the project and asking whether they were happy to receive further information about becoming involved. If the family expressed interested in finding out more, this was followed up by a phone call to discuss the project and an offer of a visit for further conversations if the family wished. A small number of families went through this process and all were given the opportunity to remain involved for as long as they wanted for the duration of the research.

I agreed a bespoke schedule and format for visits, which provided the opportunity for discussion and observation, fitting around the routines of family life. Over time this built up opportunities for participation in elements of the family's activities. An additional element was the use of visual ethnography, using drawing exercises to produce collaborative data (collaboration between multiple family members), to record imaginative representations of family life and to elicit discussion of different perspectives held within the family. These research methods were used over a period of nine months, while the families experienced both continuity and change in their lives, with increasing familiarity between them and the researcher. The data consist of fieldnotes, which include verbatim quotations, drawings from participants and the researcher's reflective writing.

I built activities into the fieldwork and analysis process to support the trustworthiness of the data. One strand was checking my notes and plans with participants. I discussed the research design with young carers and young carer project workers to get their feedback on how to initiate the research process and prepare ways of checking my work with my participants. During the fieldwork process I typed up verbatim quote, observations and analysis points on an electronic tablet whilst I was present with young carers and their families. I was able to check the accuracy of these notes during fieldwork and participants could review my notes. Immediately after each visit I would jot down points that I had retained as 'headnotes' (Hammersley \& Atkinson, 2007). Fieldnotes were worked on further by adding descriptions and reflections in the hours and days after each visit in order to build a detailed picture so that the material was fresh. My participants were offered the opportunity to see a draft of my thesis and two of my participants did so, providing some comments in response, which I took on board.

A number of other people's perspectives were sought to challenge or explore this process and increase trustworthiness. I shared sections of fieldnotes and visual data with my $\mathrm{PhD}$ supervisors who could give their perspective on the fieldwork and feed into the process of reflection. I also 
shared extended quotes and the developing analysis with peers at conferences in order to gain feedback on the methodological approach.

Alongside checking with my participants and others in the academic community, I undertook reflexivity. I regularly updated a research journal which aided my momentum in reflecting on my activities, my positionality and the emotions connected to fieldwork (Spradley, 1980). Reflexivity influenced my thinking on the ethnography (Aull Davies, 1999), reaching a point of producing the analysis based on my experience of getting closer to participants, feeling the distances and closeness between us.

To protect the families' privacy, participants chose pseudonyms, which are used here. They also imposed limits on subjects discussed and commented on the data as it was collected. They provided their consent to participate in the study and reviewed their participation to confirm they agreed to the process as it developed. Efforts were made to provide opportunities for individual family members to share their experiences but there was an acceptance that this could not be confidential and could be known by others in their families through the ethnographic research process (Eldén \& Anving, 2020).

\section{Findings on the Conditions of Care for Young Carers and Their Families: Class and 'Race'}

The study found that young carers and their families were socially located at the intersections of multiple inequalities. In analysing their positive and negative experiences of services I referred frequently to explanations grounded in their social location. The participants would also draw on their understanding of their class, 'race'/ethnicity, disability, citizenship status and religion to interpret the nature of their encounters with professionals that addressed them as families with issues relating to disability and as including a young carer. Inequalities affected the experience of being a young carers, of being their sibling or their parent, interacting with the circumstances of disability and complex physical, mental, emotional and practical needs.

During the ethnographic fieldwork, spending time with families, I was presented with data from families about the way that they experienced their relationship to categories of social difference, such as ethnicity/'race' and class. There were differences in the ways that families presented their social location. Some of the data was articulated directly or remained more implicit. This is discussed as a contrast of spoke and unspoken social locations. Another differences in the families' relationships to inequalities was whether they had experienced privileged or subordinated position. This is a second set of contrasts that I discuss here, as well as considering the significance of these forms of representation of social location for understanding the families' conditions of care.

I explore two case studies of class and 'race' as conditions of care for young carers and their families. This is followed by a discussion of the conditions of care for this group of young carers and their families in the West Midlands region in England. The data comes from interactions with young carers but also siblings and parents because the overlapping relationships between family members helps us understand the way that 'whole family' policies are interacting with inequalities in their lives.

\section{Alia's Family}

One group of participants was Alia's family. She lived with her mother, Kaya, her father, Ben, and older sister, Amber. Alia was a young carer who received support through a local young carers service because she was regularly providing care for her older sister. They held a British Pakistani, middle class identity foremost, but also saw Amber's disability as something they all shared as an experience. The management of Amber's needs was very absorbing (McLaughlin, 2006) and family life was vocalised through the lively and absorbing activities of motherhood, fatherhood, daughterhood and sisterhood. A cast of wider family members were recalled in conversation, invited in or visited. Family life was going at full pace and with many references to the categories that placed the family as a whole in their social world and that differentiated between Alia, Amber, Kaya and Ben.

Alia's family shared with me a culture of discussion and debate. They were keen to speak about their social location, where it established positive treatment and where it incurred discrimination. Alia's family provided an example of how 'race' and ethnicity are important explanatory frameworks for families' encounters with the support services targeting families with a disabled person as a member and young carers. Alia and her mother, Kaya, articulated the ways that they were stereotyped and their frustration with the ways that other people pursued lifestyles that contributed to a stereotype of behaviour based on religion and 'race' (Mirza, 2013). Kaya explained how social workers accused her of not properly providing for her eldest daughter, Amber, and that there was a suspicion that she was a possible victim of forced marriage. Kaya perceived that these accusations were based on stereotyping the family because of their Islamic faith and their South Asian ethnicity. She was determined to show that they were false and ridiculous.

\section{Fieldnotes 25/3/18}

Kaya was hurt, offended and angered by a suspicion that Amber was at risk of forced marriage during a period when she was taken out of school because bul- 
lying meant that she refused to go. She stayed in Pakistan for several months with her grandparents. Kaya said that this showed her "how racist the social workers and schools could be." She contrasted that forceful interaction with the disengagement when she raised concerns about Amber's poor education. She spoke very evocatively about insisting that the social worker went around to see the house and that she needed to see the food supplies to refute that idea that the children were not fed enough.

This interaction with social workers was significant for the ways that it made Kaya feel that she and her family were racialised subjects, reduced to the performance of acts in line with a stereotype of Muslim citizens. Yet the engagement with the state on the family's terms, seeking support for Amber's education and mental health services were denied. Kaya felt disempowered by the ways that the family's attempts to manage the pressures of disability and care were undermined by racialised terms for their interactions with state services. She felt that there were "so many levels of prejudice there." (Fieldnotes 4/6/18). Ethnicity and religion were intersecting social structures that had impressed themselves upon the families' encounter with services. It was important for this family to speak about the ways that this position of subordination was experienced. It was part of their conditions of care, producing difficult feelings about working with services and accepting offers of support.

Kaya was attentive to her class position, her high level of education and the professional jobs that gave her and her husband considerable resources and financial security.

\section{Fieldnotes 25/3/18}

Kaya implied that because the family are affluent and highly educated (implicitly middle class, I suppose), that they were dismissed as not needing the input of services.

Kaya felt that her class position complicated her relationship with services, made it difficult for her to navigate and also meant that she did not have the position of power that she was used to holding. She could not express middle class behaviours, instead having to fight for resources that she should have been entitled to. She also noted the different background of those whose circumstances meant they were brought together by their connection to services for children with special needs.

\section{Fieldnotes 25/11/18}

Kaya spoke about how many of the other young people in Amber's school "came from chaotic and impoverished families," who were "unable to help them with administrative tasks because they have not gained much from the educational system."
Social workers, staff at the college for students with special educational needs and child psychologists were also figures in Kaya's interaction with the welfare state that had required her to confront hierarchies of class, 'race', ethnicity and migration.

Kaya's younger daughter, Alia, a young carer, indicated some familiarity with these same structures of inequality and social categories of difference. Alia referenced class when she drew on her experience of defending herself because of accusations of superiority. It suggested to me that she also had to navigate divisions of class with her peers and that she replicated these difficult manoeuvres in recounting a family story during a research visit.

\section{Fieldnotes 3/8/18}

During [a story about her aunt's profession] Alia made two comments that added to the picture of social location. She said about her aunt being one of the top doctors and then said that she is "not boasting, that it's true." People at school had accuse her of boasting. I wondered how this builds an idea of class, education and race that people might reject, through this idea of boasting. Alia also checked that I knew that Abu meant granddad, which I did. I think I knew that but maybe it was from context, just guessing. It was interesting the ways that Alia's questioning was showing how she saw the differences in me.

Public spaces were discussed at home, reflecting on the ways that 'race' and ethnicity impacted on these experiences. At the same time, my presence in that environment as a researcher, representing a intersectional identity (white, middle class woman, not disabled, English accent) establish a set of shared assumptions and differences that drew comment.

The experience of educational institutions was a prominent feature of families care biographies. Educational institutions were important public spaces where 'race' intersected with class and gender (Lareau, 2011; Reay, 2017). Alia explained some of the ways that ethnicity and nationality fractured the social relations in her school.

\section{Fieldnotes 3/8/18}

Alia says that "the Bangladeshi girls at school" think that she is "weird" because she does not pray after school. Kaya said that "they are racist against them" [the family or Pakistanis, I'm not sure]. Alia said that "they are jealous because I was the only brown girl who would make friends with people who are not brown." Kaya says that she thinks it is because they were jealous that she "did not have to live in that oppressive lifestyle." Alia talked about how more recently the Bangladeshi girls made friends with a girl who was white and after saying white she quickly said "no offence" to me, which amused me. Alia said that 
people at school "tell her off and get uncomfortable" when she talks about race or talks about someone 'as white'. She mocked people who are so uncomfortable talking about race. She is glad that her "friendship group is mixed because then they won't have problems about race. At primary school there were problems." Kaya said that her friends have "always been mixed." You then get a taste of "their own culture," they said. They seemed harmonious on this topic and enjoyed building on each other's ideas to mark out their views on race.

Noting a 'white' audience for this explanation embodied by the researcher, Alia describes frustrations and amusements about ethnic differences. These experiences were located outside of family life, while Alia enjoyed the freedom to associate herself with diverse people, as did her mother. The constraints and conflicts of the educational environment were contrasted with the relative freedom and harmony of their family life.

Alia's parents supported their daughter in diagnosing the prejudices that were encountered through interactions with services or in school and they spoke of how they used family life as a space in which to respond creatively and resist these harmful currents.

\section{XD's Family}

Like Alia's family, the information that XD and his mother shared helps elaborate the way that the intersection of class, ethnicity, 'race' and nationality anchored their family identity and was articulated in their encounters with services. $\mathrm{XD}$ and his mother were Black and they had migrated to the UK from southern Africa. The process of arriving in the UK, to join XD's father, was the start of a difficult legal process. Tizzy, XD's mother was in the country under restrictive terms as since her separation from XD's father she no longer had right to be in the country as his dependant. Therefore, she did not have the right to work or to access a range of benefits. The disintegration of her relationship with XD's father, who was violent towards her, left her without financial support and unable to earn through paid work because of the laws applied to migrants. She was living with XD in poor housing, which from the outset of my time with them, they discussed as extremely difficult. Tizzy felt lost and unable to be independent as she had used to be when she had been able to do paid work before she migrated. Her mental health deteriorated and she struggled to look after XD. Support from social services was credited with enabling an improvement in her mental health. She had also found it helpful to receive counselling and the attentions of housing services. Following this period she was able to reconnect with the responsibilities to look after XD. Nevertheless she was still unable to look for paid work so she had to manage the welfare payments carefully to cover the costs of everyday life. Tizzy and XD's circumstances were heavily imprinted by the criminalisation of migration and connect them to a picture of the ways that women and children have their lives shaped by violence against women (Walby et al., 2017). XD was put in the position of being Tizzy's carer and taking on extensive domestic responsibilities including cooking and cleaning. He was referred to the young carers' services and attended regular activities sessions, social groups and had professional staff keeping an eye on his situation.

XD recognised the importance of class for understanding other people's backgrounds, although not sharing his thoughts about how it applied to himself. When reflecting on his mother's story of long hours doing housework and providing care for relatives when she was a child,

\section{Fieldnotes 24/9/18}

He said he did not know "if they were working class or well off but it was really hard" for his mum.

Class was a reference point but migration, nationality and mental health were prominent in their account of evolving care needs.

The family had been bullied and targeted for criticism because of the ways that people sharing the house interpreted their ethnicity and class. Tizzy and XD had been accused of being a spies for the Home Office by other residents in their shared housing because they were seen to be in a relatively favourable position (having a bedroom each, although this was required by the local authority housing rules because of XD's gender and age). Tizzy also explained that XD was perceived as being born in the UK because his accent placed him as local, rather than someone who was a migrant by background. Time spent with Tizzy and XD during fieldwork showed that they enjoyed recounting stories about the times in southern Africa, its landscapes, its culture, its economy and their family there. Nationality and migration were reference points for XD and his mother to tell their story, explain the struggles of the last few years and consider their options for the future.

Migration was a strong theme in their story, while ethnicity or 'race' were less openly explored. My positionality and habituation with the invisibility of whiteness (Clark Mane, 2012) may have influenced me to be tentative in discussing 'race' and ethnicity in contrast to pursuing more extensive questioning about gender or disability. The lack of discussion about ethnicity and 'race' may reflect XD's discomfort at representing his ethnicity to a white British woman, not confident about the response he would get (Konstantoni \& Emejulu, 2017).

However, in one discussion, XD used 'race' and ethnicity as a reference point when telling a story about his family. 
Table 2 Families' representation of their social location in relation to class and 'race'/ ethnicity

\begin{tabular}{lll}
\hline & Spoken & Unspoken \\
\hline $\begin{array}{l}\text { Categorising the unequal condi- } \\
\text { tions of care }\end{array}$ & & \\
$\begin{array}{l}\text { Privileged } \\
\text { Subordinate }\end{array}$ & Middle class families & White British families \\
\hline
\end{tabular}

\section{Fieldnotes 22/10/18}

$\mathrm{XD}$ did not seem to know the cousins. Tizzy referred to them carrying him when he was little. XD asked if the cousin they are referring to "is the black man, the dark man." Tizzy was laughing at the reference. She laughed "as if you were white! He is like your cousin!". XD dismissed her jokes and said that he just did not remember what he looked like.

Their Black identity was something that Tizzy expected XD to be clear about, not to forget. The idea of him questioning it by implying their family were anything but Black was ridiculous to her. He seemed to see it differently, with lower expectations about the absolute nature of their Black identity and that of their family. He also questioned his mother's instruction to reject his group of friends in the neighbourhood because of racist behaviour, implying that he did not see this as the correct judgement about them and regretting the loss of their friendship because it meant he was lonelier when away from school. Tizzy and XD had different interpretations of their social location. XD saw 'race' and nationality as less relevant to his life, while Tizzy felt their importance for the continuities in her life, herself as a Black woman from southern Africa.

This background triggered XD's role as a young carer. $\mathrm{He}$ needed to step in when Tizzy was overwhelmed with distress and the after effects of the breakdown of her relationship, cut off from her family and without economic resources. In other words, the family found themselves disconnected from their middle class background and having to start again in a new position because of their migration status. They encountered a very different landscape of welfare services, which helped them get back onto their feet but did not remove the legal constraints because of their status as immigrants (Berg et al., 2019; Jolly, 2019; Kilkey et al., 2013; Mirza, 2013). 'Race', ethnicity and class were important markers in exploring the family's circumstances and understanding XD's position as a young carer.

\section{Representing and Interpreting the Conditions of Care}

The analysis of the data on class, 'race'/ethnicity and the social location of young carers and their families illustrates two ways of categorising the unequal conditions of care. I produced two categorisations based on the analysis of social location from the ethnographic research. My analysis was underpinned by charting the process by which individuals disclosed social location and by synthesising the social location data from different family members. I also analysed the way that different social locations were embodied by family members, weaving inequalities and social hierarchies into the network of relationships held within the family. Lastly, I considered how the data was shaped by my embodied presence as a researcher. Taking insights from each of these perspectives on the unequal conditions of care, I present two categories that help us explore the lives of young carers in the West Midlands. I argue that applying two contrasting labels, spoken/unspoken and privileged/subordinated, helps us to understand the intersectionality of the relationships between young carers, families and services (see Table 2).

The four labels shown in Table 2 set out different ways that social locations were constructed through the ethnography process. I argue that in this specific context and in conversations with this particular researcher, families spoke about and also left unspoken their connection to the categories of 'race'/ethnicity and class. Their positions were also underpinned by structures that privileged or subordinated them. These categories shed light on the unequal conditions of care and services for young carers. 'Race'/ethnicity and class intersect in the ways that family members experienced their relationship to public services and interpreted the decisions about their entitlements. These categories of young carers and their families are now discussed further in relation to researcher positionality and the unequal conditions of care, drawing on intersectionality theory. 


\section{Researcher Positionality and Speaking About Privilege}

As a white, middle class, 'able-bodied' woman, I had limited embodied knowledge to build up the voices of those who are subordinated at the intersectional of ethnicity, class, disability and other categories of social difference (Hill Collins \& Bilge, 2016; Harding, 1993; Konstantoni \& Emejulu, 2017; Mirza, 2013). The data on 'race'/ethnicity and class is marked by the limitations of knowledge I had as a researcher and the ways that my identity inhibited or encouraged the sharing of experiences by my participants. It is likely that the positionality of the researcher in this case, as a middle class woman facilitated discussions about middle class identity more than it would have for a discussion of working class experiences. My background meant I was tuned into the implications of certain comments. I might also have been seen as more sympathetic or receptive.

The middle class families in the study, for example, Alia's family spoke freely about middle class experiences, as did another family, Rosie's family. The experiences of families embodying a middle-class status to engage with services was something that two families explained to me. They had learned which elements of their intersectional identity helped them, giving them greater control, extra resources, a stronger voice or some more power in the interactions with services.

For Rosie and Alia's families, their mothers reported some of the ways that services had interacted with their families and sought to respond to the needs of their daughters as young carers. These participants drew connections between their class position and the ways it distinguished them other people who were connected to state provision. In both cases, the mothers used education as evidence of their strengthened position to negotiated services for their daughters and indicated that they felt out of place in the interactions with professionals or state representatives.

\section{Fieldnotes 16/5/18}

Dominique [Rosie's mother] spoke of her anger at her treatment by the legal system. For example, [Children and Family Court Advisory and Support Service] staff acted "superior" but seemed not to be able "to handle" Dominique and her ex-partner because they are both "educated and intelligent." Dominique felt that they were "used to dealing with people who are more rough."

In this extract from fieldnotes and the extracts in the discussion of Alia's family the women drew distinctions between their status and other parents who were placed in similar relationships to services because of circumstances such as children's special educational needs, their children's roles as young carers or disputes adjudicated through the family courts.

Both women also provided moments where I could observe the ways that they educated their daughters in reproducing class status. Dominique picked up on her daughters' pronunciation, gently mocking her and discouraging her from speaking in ways that exacerbated the West Midlands inflection in their words. Middle class performance was monitored in the young carer's domestic interactions. In return for been cultured in middle class ways, the middle class young carers were benefitting from increased supportive input from services. Rosie's family secured access to funding for respite services so that Rosie could have time with her mother while her sister Poppy had one-to-one care. Alia's family had been effective in gaining the input of an educational psychologists for Alia's older sister so their was a professional addressing their concerns about her educational needs. The whole family approach promoted by the Care Act 2014 and the Children and Families Act 2014 in England appears to be working in some cases for middle class families, with them using their privileged position and being legitimated to speak about their social location.

The middle class privilege did not exist in isolation from other class positions that were subordinated. The young carers, Rosie and Alia could benefit from the way that their mothers deployed their class position, in the rhetorical tactic of being different from 'the rest'-i.e. from the working class people who were seen as the regular subjects of those services. This perpetuated the idea that services could usually work in ways that gave citizens little power, with the exception for middle class subjects who 'pulled rank'. The working class subject was reinforced as one who had to submit to the system or had to draw on other categories if they were to modify their experience of public services. Class was an important resource for securing what the family needed to support disabled children and young carers.

The working class families recounted experiences of services in which they were the subject of compulsion. One family had to engage with the youth justice system following a caution for shoplifting. Another family shared difficult memories of intervention from social services. Whilst the young carers did benefit from specialist services, their lack of wider supportive services was notable, in contrast with the middle class young carers. They did not present the same set of examples of having support services address the family's care needs in order to reduce the work carried out by young carers and improve their day to day experiences.

Working class status was not a prominent rhetorical resource as recorded in this ethnography. The limited discussion of working class experiences might indicate a wariness of using me as an audience for these experience. Alternatively, it might reflect my limited knowledge to draw on 
markers and shared experience of working class life, therefore a shortcoming when it came to identifying and recording the points about working class experience.

With this qualification about the problems of accessing these accounts, it is also interesting to consider whether the lack of working class expressions captured here may also reflect its exclusion from families' narratives. Whilst middle class status was indicated to be a helpful resource for the two families discussed above, working class status may have been put to one side in the interaction with services, not offering the same benefits. The ability to assert the presence of disadvantaged and treatment through services may be hindered by cultures that subordinate working class families but also discourage spoke identification with this subject position.

\section{Spoken and Unspoken Representations of Inequality in the Conditions of Care}

The conditions of care were made more favourable for those families that could draw on the resources of middle class identity. They could command a different position when they interacted with services and could draw strength from expectations of support.

Whilst there are suggestions that White British ethnicities also conferred a position of privilege, sparing those families the difficulties of navigating the assumptions or discrimination that Alia's family described, this took on a different form in the data. It was also an identity position shared with the researcher but rather than being a spoken position of privilege it was emphatically unspoken by those families that benefited from it.

Other than point to this omission, what can we say about white ethnicity in this study and its connection to the earlier richer discussion about South Asian ethnicity and Black identity? Alia, a young carers, provides a rare example of discussing whiteness, talking about how she shocked her peers at school in naming it as a category. The taboo of naming whiteness has probably imprinted itself on the data, reducing the possibilities of analysing the privilege built around this category. However, it is important than white ethnicity does not go unremarked in the analysis, despite its ability to slide out of discussion, as an unremarked-upon assumed state (Clark Mane, 2012; Konstantoni \& Emejulu, 2017; Tomlinson, 2018). The presence of a white British researcher would ease the invisibility of whiteness in these conversations, allowing it to be unremarkable or potentially harder to utter. It is also interesting to consider that the white families were able to exclude ethnicity from their consideration about relationships with services, while for Alia's family in particular, they needed to develop their knowledge, awareness and strategies to overcome the ways that racism might operate through the delivery or denial of services. The need to explain, to account for and to reconcile views within the family for some are connected to the ease of living without conscious reference to ethnicity, which some of the families were able to experience. Despite being absent, whiteness was important in that it subtly provided protection and resources, but in ways that were varied because it intersected with migration and class status.

The study provides material for an exploration of the ways that the category of 'race' and ethnicity intersect with class to shape the experiences of young carers and their families. This is the case for those in subordinated positions but also privileged ones. It confirms that the gap in research about social inequalities and young carers is indeed problematic (Aldridge, 2018; Jones et al., 2002; Vizard et al., 2019). What is distinctive about the argument here is that the experience of those young carers that are middle class, that are socially located as White British could also be better understood as part of further research that explicitly addresses those privileged identities, as well as a need to rectify the lack of understanding of the experiences of young carers who are Black and Minority Ethnic and working class. Those in privileged positions are typically shielded from the expectation that they articulate the relationship to these categories (Clark Mane, 2012; Spelman, 1988; Tomlinson, 2018). There is a failure in the literature on Minority World young carers to attend to subordinated voices but also to articulate the intersections of privileged young carers' subjectivities, thereby making intersecting inequalities even more invisible.

In considering researcher positionality but also analysing the ethnographic data, intersectionality theory provides a framework for paying attention to the way that privileged positions can be present but hidden, potentially taken for granted or obscured (Hancock, 2016; Mirza, 2015, Spelman). In this context middle class privileges were explored by families in their discussions with the researcher, while privileges of whiteness were left implicit. Further research into privileged and subordinated positions of young carers should therefore consider different representations of social location and would benefit from the involvement of researchers bringing different embodied knowledge of inequalities (Harding, 1993).

\section{Conclusion}

The study found impacts of inequalities of ethnicity/'race' and class, which affected children's access to support as young carers. The supportive quality of services was compromised by these persistent inequalities, with families disadvantaged and facing discrimination. The particular methods described here, with study participants shared the 
experience of their family life for a period of participant observation, allowed me to explore ideas of spoken and unspoken intersections of categories of social difference in the lives of young carers. Intersecting inequalities of 'race'/ ethnicity and class place families in different positions in relation to services, some privileged and some subordinated. The unequal conditions of care concept draws attention to the ways that power is exerted at the interface between families and services as mediated by policies, across two categories of spoken/unspoken and privileged/subordinated. Positions of 'race' and class are reference points to understand how families are positioned by those working in public services or as agents of policy implementation within the third sector. Families that occupied relatively strong positions were those whose ethnicity was characterised by whiteness and held middle class status but they mainly observed a silence about whiteness, not needing to use it explicitly as a reference point to interpret their position as recipients of services. I found that a position of privilege in the category of class, a middle class identity, was important knowledge for explaining a strained but favourable relationship with services, although ethnicity marked out middle class families differently. Working class identity was less alluded to, but middle class identity was an important resource in pushing back against the instructions, intrusions or reticence of state provision. The implementation of the Care Act 2014 and the Children and Families Act 2014 that provide for young carers in England are being shaped by relations of inequality within families, between families and in interactions with services.

An intersectional perspective and a prominent use of it within analysis is needed for an understanding of how policies take on a different character, more or less supportive, more or less punitive, in the ways they reach young carers and their families. This is because it holds our analysis to account, reminding us to examine those subject positions that are unspoken, giving a fuller picture of privileges and subordination. It also asks to "substantively attends to what comes into view." (Hancock, 2016, p. 48), to reshape our understanding of the world in response and act on it. So where might our new perspective direct us? Services could consider and address the lack of support or the problematic aspects of services offered to working class families and Black and Minority Ethnic families. This adds to existing calls for services to improve their support to this group made by Jones et al. (2002). It would also be beneficial to consider that ways that improving the circumstances of young carers is dependent on wide efforts to confront inequalities of 'race'/ethnicity, class and disability and promote social justice. The role of young carers is related to the way that families see the need of children and adults to be supported. Prominent ideas about disability, gender, sexuality and age encourage needs to be heavily stated, whilst other family members are seen as more independent of support. This means that the fates of children inhabiting young carer roles are intertwined with existing and future prejudices about disability, gender, sexuality and age. Efforts to explore these prejudices in the general population and in family cultures or to challenge discriminatory attitudes could unpick some of the ways that care needs are worsened and under-resourced, increasing the work potentially done by young carers. The campaigning work of disability advocates, antiracist activists, feminist campaigners and LGBTQ + advocates to challenge those attitudes could lead to a shift in family care requirements. Lessening inequalities and securing more socially just provision for disadvantaged groups could change the conditions that create care need and replenish the resources that support individual and collective wellbeing. Intersectional analysis provides such insights into the nature of care and possible avenues for policy.

As young carer research is circulated internationally amongst academic communities and policy-makers, the most influential interpretations of this topic are dominated by Minority world conceptualisations of young carers (Evans \& Becker, 2019). These have not yet adequately been informed by a consideration the experiences of more marginalised young carers' in these locations, which are fundamentally shaped by poverty and inequalities. Neither do these critically consider the ways that the 'typical' young carer experience may be reliant on unspoken forms of privilege such as white ethnicity. Therefore, international policy work on this topic should take into consideration the critical gaps in knowledge on young carers in the Minority world and its limitations as a template for approaches elsewhere. By developing an understanding of the unequal conditions of care that surround and shape the experiences of young carers, the literature on young carers in the Minority World can be strengthened and be a more nuanced resource for research taking place in other contexts.

Acknowledgements I am extremely grateful to the families that participated in the study. I would also like to thank Caroline Alexander, Andrew Alexander, Claudia Wright and Jeffrey Wright, the informal childcare team that supported my work on this paper.

Author Contributions Not applicable.

Funding Funding for the work was generously provided by the University of Birmingham School of Social Policy Studentship and a Postdoctoral Policy Impact Fellowship funded by the UKRI Quality-Related Research Fund.

Data Availability Not applicable.

Code Availability Not applicable. 


\section{Declarations}

Conflict of interest Not applicable.

Open Access This article is licensed under a Creative Commons Attribution 4.0 International License, which permits use, sharing, adaptation, distribution and reproduction in any medium or format, as long as you give appropriate credit to the original author(s) and the source, provide a link to the Creative Commons licence, and indicate if changes were made. The images or other third party material in this article are included in the article's Creative Commons licence, unless indicated otherwise in a credit line to the material. If material is not included in the article's Creative Commons licence and your intended use is not permitted by statutory regulation or exceeds the permitted use, you will need to obtain permission directly from the copyright holder. To view a copy of this licence, visit http://creativecommons.org/licenses/by/4.0/.

\section{References}

Akkan, B. (2020). An egalitarian politics of care: Young female carers and the intersectional inequalities of gender, class and age. Feminist Theory, 21(1), 47-64. https://doi.org/10.1177/14647 00119850025

Aldridge, J. (2018). 'Where are we now? Twenty-five years of research, policy and practice on young carers.' Critical Social Policy., 38(1), 155-165. https://doi.org/10.1177/0261018317724525

Aldridge, J., \& Becker, S. (2003). Children caring for parents with mental illness: Perspectives of young carers, parents and professionals. Policy Press.

Alexander, C. (2015). Time to be heard: A call for recognition and support for young adult carers. Carers Trust.

Alexander, C. (2021). Affects of policy design: The case of Young Carers in the Care Act 2014 and the Children and Families Act 2014. Social Policy and Administration. https://doi.org/10.1111/ spol.12692

Aull Davies, C. (1999). Reflexive ethnography: A guide to researching selves and others. Routledge.

Berg, M. L., Gidley, B., \& Krausova, A. (2019). Welfare micropublics and inequality: urban super-diversity in a time of austerity. Ethnic and Racial Studies, 42, 2723-2742.

Brannen, J., Heptinstall, E., \& Bhopal, K. (2000). Connecting children: Care and family life in later childhood. RoutledgeFalmer.

Brimblecombe, N., Knapp, M., King, D. et al. (2020). The high cost of unpaid care by young people: health and economic impacts of providing unpaid care. BMC Public Health, 20, 1115. https://doi. org/10.1186/s12889-020-09166-7.

Bronfenbrenner, U. (1979). The ecology of human development: Experiments by nature and design. Harvard University Press.

Butler, A. H., \& Astbury, G. (2006). The caring child: An evaluative case study of the Cornwall Young Carers project. Children \& Society, 19, 292-303.

Camiletti, E., Banati, P., \& Cook, S. (2018). Children's Roles in Social Reproduction: re-examining the discourse on care through a child lens. Law, Social Justice and Global Development, 21, 33-48.

Carers Trust and University of Sussex. (2021). Enabling young carers to pursue their goals in life and reach their full potentialConverting research findings into policy actions. Country Focus: United Kingdom. Accessed 16 Aug 2021 at https://me-we.eu/wpcontent/uploads/2019/06/Me-We-policy-brief-UK.pdf.

Cheesbrough, S., Harding, C., Webster, H., Taylor, L., \& Aldridge, J. (2017). The lives of young carers in England: Omnibus survey report. Department for Education.
Children's Commissioner for England. (2016). Young carers: The support provided to young carers in England. Children's Commissioner for England.

Clark Mane, R. L. (2012). Transmuting grammars of whiteness in third-wave feminism: Interrogating postrace histories, postmodern abstraction, and the proliferation of difference in third-wave texts. Signs, 38, 71-98.

Cohambee River Collective. (1983). A black feminist statement. In G. Anzaldúa \& C. Moraga (Eds.), This bridge called my back: Writings by radical women of color (2nd ed.). New York: Kitchen Table-Women of Color Press.

Crenshaw, K. (1989). Demarginalizing the intersection of race and sex: A black feminist critique of antidiscrimination doctrine, feminist theory and antiracist politics. University of Chicago Legal Forum, 140, 139-167.

Crossley, S. (2016). Realising the (troubled) family', 'crafting the neoliberal state. Families, Relationships and Societies, 5, 263-279.

Ehrenreich, B., \& Hochschild, A. R. (2003). Global woman: Nannies, maids and sex workers in the new economy. Granta Books.

Eldén, S., \& Anving, T. (2020). Nanny families: Practices of care by nannies, Au pairs, parents and children in Sweden. Bristol University Press.

Evans, R., \& Becker, S. (2019). Comparing children's care work across Majority and Minority worlds. In A. Twum-DansoImo, M. Bourdillon, \& S. Meichsner (Eds.), Global childhoods beyond the North-South Divide. Palgrave.

Gabb, J. (2008). Researching intimacy in families. Palgrave Macmillan.

Geertz, C. (1973). The interpretation of cultures: Selected essays. Basic Books.

Hamilton, M., \& Cass, B. (2017). Capturing the centrality of age and life- course stage in the provision of unpaid care. Journal of Sociology, 53, 79-93.

Hammersley, M., \& Atkinson, P. (2007). Ethnography: Principles in practice. Routledge.

Hancock, A.-M. (2016). Intersectionality: An intellectual history. Oxford University Press.

Harding, S. (1993). Rethinking standpoint epistemology: What is "strong objectivity"? In L. Alcoff \& E. Potter (Eds.), Feminist epistemologies. Routledge.

Hill Collins, P., \& Bilge, S. (2016). Intersectionality. Polity Press.

James, A. L., \& James, A. (2001). Tightening the net: Children, community, and control. British Journal of Sociology, 52, 211-228.

Jolly, A. (2019). From the Windrush Generation to the "Air Jamaica generation": Local authority support for families with no recourse to public funds. Social Policy Review, 31, 129.

Jones, A., Jeyasingham, D., \& Rajasooriya, S. (2002). Invisible families: The strengths and needs of black families in which young people have caring responsibilities. Policy Press.

Kelly, G., Devine, P., \& McKnight, M. (2017). Lost in translation? The challenges of measuring informal care among children and young people. International Journal of Care and Caring, 1(3), 389-407. https://doi.org/10.1332/239788217X15084960724368

Kilkey, M., Perrons, D., \& Plomien, A. (2013). Gender, migration and domestic work: masculinities, male labour and fathering in the $U K$ and USA. Palgrave Macmillan.

Konstantoni, K., \& Emejulu, A. (2017). When intersectionality met childhood studies: The dilemmas of a travelling concept. Children's Geographies, 15, 6-22.

Lareau, A. (2011). Unequal childhoods: Class, race, and family life. University of California Press.

Leu, A., \& Becker, S. (2017). A cross-national and comparative classification of in-country awareness and policy responses to "young carers". Journal of Youth Studies, 20, 750-762.

Lorde, A. (1984). Zami : A new spelling of my name. Sheba. 
Marx Ferree, M. (1990). Beyond separate spheres: Feminism and family research. Journal of Marriage and Family, 52, 866-884.

McLaughlin, J. (2006). Conceptualising intensive caring activities: The changing lives of families with young disabled children. Sociological Research Online, 11, 1-11.

Mirza, H. S. (2013). 'A second skin': Embodied intersectionality, transnationalism and narratives of identity and belonging among Muslim women in Britain. Women's Studies International Forum, $36,5-15$.

Mirza, H. S. (2015). "Harvesting our collective intelligence": Black British feminism in post-race times. Women's Studies International Forum, 51, 1-9.

Oakley, A. (1974). The sociology of housework. Martin Robertson.

Office for National Statistics. (2013). Providing unpaid care may have an adverse affect on young carers' general health. Office for National Statistics.

Parr, S. (2017). Explaining and understanding state intervention into the lives of "troubled" families. Social Policy and Society, 16, 577-592.

Reay, D. (2017). Miseducation: Inequality, education and the working classes. Policy Press.

Santini, S., Socci, M., D’Amen, B., Di Rosa, M., Casu, G., Hlebec, V., Lewis, F., Leu, A., Hoefman, R., Brolin, R., Magnusson, L., \& Hanson, E. (2020). Positive and negative impacts of caring among adolescents caring for grandparents results from an online Survey in Six European Countries and implications for future research, policy and practice. International Journal of Environmental Research and Public Health, 17, 6593.

Sempik, J., \& Becker, S. (2013). Young adult carers at school: Experiences and perceptions of caring and education. Carers Trust.

Shelton, B. A., \& John, D. (1996). The division of household labor. Annual Review of Sociology, 22, 299-323.

Spelman, E. V. A. (1988). Inessential woman : Problems of exclusion in feminist thought. Beacon Press.
Spradley, J. P. (1980). Participant observation. Holt, Rhinehart and Winstone.

Thomas, N., Stainton, T., Jackson, S., Cheung, W. Y., Doubtfire, S., \& Webb, A. (2003). 'Your friends don't understand': Invisibility and unmet need in the lives of 'young carers. Child \& Family Social Work, 8, 35-46.

Tomlinson, B. (2018). Category anxiety and the invisible white woman: Managing intersectionality at the scene of argument. Feminist Theory, 19, 145-164.

Traynor, P. (2016). Young people caring OUT there: Experiences of LGBT young adult carers in Scotland. Carers Trust Scotland.

Vizard, P., Obolenskaya, P., \& Burchardt, T. (2019). Child poverty amongst young carers in the UK: Prevalence and trends in the wake of the financial crisis, economic downturn and onset of austerity. Child Ind Res, 12, 1831-1854. https://doi.org/10.1007/ s12187-018-9608-6

Warren, J. (2007). Young carers: Conventional or exaggerated levels of involvement in domestic and caring tasks? Children \& Society, $21,136-146$.

Walby, S., et al. (2017). The concept and measurement of violence against women and men. Policy Press.

Yeandle, S., Chou, Y.-C., Fine, M., Larkin, M., \& Milne, A. (2017). Care and caring: Interdisciplinary perspectives on a societal issue of global significance. International Journal of Care and Caring, $1,3-25$.

Publisher's Note Springer Nature remains neutral with regard to jurisdictional claims in published maps and institutional affiliations. 